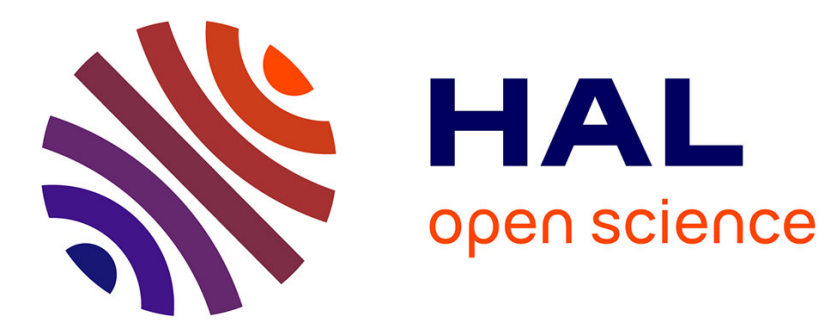

\title{
Kite Generator System Modeling and Grid Integration
}

\author{
Mariam Ahmed, Ahmad Hably, Seddik Bacha
}

\section{To cite this version:}

Mariam Ahmed, Ahmad Hably, Seddik Bacha. Kite Generator System Modeling and Grid Integration. IEEE Transactions on Sustainable Energy , 2013, 4 (4), pp.968-976. 10.1109/TSTE.2013.2260364 . hal-00873094

\section{HAL Id: hal-00873094 https://hal.science/hal-00873094}

Submitted on 9 Jan 2014

HAL is a multi-disciplinary open access archive for the deposit and dissemination of scientific research documents, whether they are published or not. The documents may come from teaching and research institutions in France or abroad, or from public or private research centers.
L'archive ouverte pluridisciplinaire HAL, est destinée au dépôt et à la diffusion de documents scientifiques de niveau recherche, publiés ou non, émanant des établissements d'enseignement et de recherche français ou étrangers, des laboratoires publics ou privés. 


\title{
Kite Generator System Modeling and Grid Integration
}

\author{
Mariam S. Ahmed, Ahmad Hably, and Seddik Bacha, Member, IEEE
}

\begin{abstract}
This paper deals principally with the grid connection problem of a kite-based system, named "Kite Generator System (KGS)". It presents a control scheme of a closed-orbit kite generator system, which is a wind power system with a relaxation cycle. Such a system consists of: a kite with its orientation mechanism and a power transformation system that connects the previous part to the electric grid.

Starting from a given closed orbit, the optimal tether's length rate variation (the kite's tether radial velocity) and the optimal orbit's period are found. The trajectory-tracking problem is not considered in this paper, only the kite's tether radial velocity is controlled via the electric machine rotation velocity. The power transformation system transforms the mechanical energy generated by the kite into electrical energy that can be transferred to the grid. A Matlab/simulink model of the KGS is employed to observe its behavior, and to insure the control of its mechanical and electrical variables. In order to improve the KGS's efficiency in case of slow changes of wind speed, a maximum power point tracking (MPPT) algorithm is proposed.
\end{abstract}

Index Terms-Renewable energy, High Altitude Wind Energy, Kite based wind systems, PID, MPPT.

\section{INTRODUCTION}

I NVESTIGATING new renewable energy resources to replace fossil fuels, is receiving an increasing attention recently. One important source of renewable energy is wind. It is considered as an ideal source, since it is infinitely sustainable and clean. This explains the global interest in exploiting its energy; actually, between 2000 and 2009, wind energy global capacity increased more than nine-fold, growing from 17.4 $\mathrm{GW}$ to $158.6 \mathrm{GW}$ [1]. That makes wind the fastest growing electric power source of all [2].

This energy is usually extracted by the means of a conventional wind turbine, which is, in general, a three-blade rotor, which converts wind's kinetic energy into electrical energy. This is done through a direct or a gearbox coupling with an electric generator. The turbine is installed on the standard electric grid via a power-electronics interface. The turbine power is controlled by the pitch and yaw blades angles, and/or the machine's generator torque. The whole conversion chain and the blades' control unit are placed up next to the rotor hub, on the turbine's tower. This technology is heading to increasing wind turbines size. One aim of this increment is to reach higher altitudes where winds are supposed to be stronger, hence has

\footnotetext{
* M. Ahmed and S. Bacha are with G2ELAB

(mariam.ahmed, seddik.bacha) @g2elab.grenoble-inp.fr

** A. Hably is with GIPSA-lab

ahmad.hablyegrenoble-inp. fr

ENSE3, Domaine universitaire, 11 rue des Mathmatiques, BP 46

38402 Saint-Martin d'Heres, France
}

more kinetic energy, as well as more stable. In fact, the amount of wind energy available for extraction increases with the cube of wind speed [3]. Another objective is to increase the turbine working area, thus blades size, with which the available wind power increases linearly.

Nevertheless, in order to insure that turbine size, hence its power, will continue to increase in the same fashion as it has in the last two decades, a simple modified upscale of current turbines will not be enough. But, significant technological advancement and change in the design are required to build turbines that are cost ${ }^{1}$ efficient [4] [5].

Apart from the previous research axis that builds upon the current wind turbine structure, another axis looks for structures that are able to extract wind energy at high altitudes: "HAWE: High-Altitude Wind Energy". These include using balloons [6], airborne wind turbines [7] [8] [9]; and tethered airfoils (kites). In the former two, electric power is generated by generators on the flying balloon or turbine and transmitted to the ground through cables, contrary to kite-based systems, in which tethered kites are used to harness HAWE in the form of mechanical power that is then transmitted to the ground and transformed into electrical via an electrical generator.

The structural simplicity of a kite-based system is accompanied by a modeling and control complexity, as the system is controlled in a spatial and temporal frame. As well as, the kite needs to be redrawn periodically due to the limitation in both the tether length and the kite's power region, an operation that consumes power.

The objective of this paper is to study an example of a kitebased system, named kite generator system (KGS), and to show how it can be optimized and controlled to produce an important average mechanical power, that is transformed into an electrical one and injected into an infinite electrical grid. The paper goes through four main sections. The first presents the kite generator system (KGS). The modeling of each part of the KGS is presented in the second section, including the kite simplified mathematical model, its produced mechanical power expression adopted in [10], and a fairly detailed modeling of the power transformation system. Section IV presents the control strategy. The strategy is divided into two axes: The first includes the search for the optimal tether's radial velocity and the orbit's period, and tracking the optimal predictive orbit. Meanwhile the second axis incorporate the control of the electric machine which is a synchronous machine with permanent magnets MS-MP, and the control of the power

\footnotetext{
${ }^{1}$ The cost includes manufacturing, transportation, construction and maintenance
} 
electronics interface that connects the machine to the grid. In section $\mathrm{V}$, simulation results are presented and discussed. The paper ends with conclusions and future work.

\section{Kite Generator System (KGS)}

The idea of exploiting wind energy using kites was first reported in 1980, when Loyd discussed the ability of a kite model based on the $\mathrm{C}-5 \mathrm{~A}$ plane to generate $6.7 \mathrm{MW}$ at wind speed $10 \mathrm{~m} / \mathrm{sec}$, which is three times the power of an equivalent fixed wind turbine [11]. Though his paper was completely ignored at the time, it is now considered a revolutionary idea expected to contribute hugely in renewable energy production. Few groups around the world are working on developing this concept, and early experiments have proven attractive potentials [12]. Proposed structures vary in kites and tethers' design and number; as well as the applied control methods. One simplified structure of a kite-based wind system, referred to as kite generator system, is shown in Fig.1 and adapted in this paper. Simply stated, the concept of a KGS is to mechanically drive a ground-based electric generator using a tethered kite. Energy is extracted from high altitudes by controlling the kite to fly with high crosswind speed. This develops a large pulling force that turns the generator, thus generating electricity. The kite, however, cannot pull constantly for the tether length is limited as is the kite power region, so it should be periodically redrawn to its initial position, consuming energy as doing so. This functioning results in a generation/consumption-cycled system, in which each cycle has two phases, a traction phase and a recovery phase. The kite orbit has the form of a lyingeight, which guarantees a high crosswind and the non-tangling and coiling of the kite tethers.

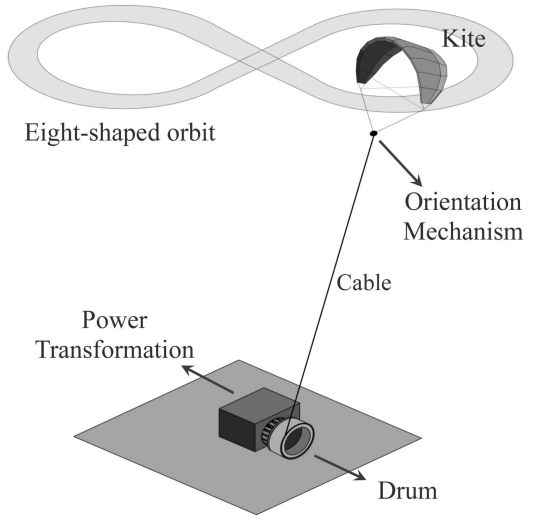

Fig. 1. A simplified Kite Generator System.

Many scenarios are suggested to extract power using such a system [13] [14] [15] [16] [17] [18]. Two are significantly more applicable than others; these are the open-orbit/pumping mode, and the closed-orbit mode. In the former mode, the kite flies consequent lying eight orbits with increasing altitude until the tether reaches its maximum length, hence the "recovery" phase starts and rolls the tether in and returns the kite to its initial position.

In the "closed-orbit mode", the kite is kept on a single eightshaped orbit, during which, two regions are distinguished: A high and a low crosswind region. In the high crosswind region, the kite pulls out the tether which result in the "traction phase", and in the low crosswind region, the tether is wound in, and that is the "recovery phase".

The KGS explained simplified structure with a closed-orbit is adapted later on in this paper. This mode's efficiency is 16 times less than that of a pumping system [19]. But it can be improved 5 times by varying the aerodynamic efficiency [19]. The closed orbit system is easier to be stabilized and controlled, as it needs one controller only, as well as it occupies a limited space [14].

\section{A. Kite Orientation}

While power generation is a direct result of pulling the tether out and turning the electrical machine, choosing a kite orbit is important to insure a maximum average power during the kite cycle, and the respect of the structural limits of the system. Directing the kite to follow this "optimal" orbit is done through an orientation mechanism, that controls the kite roll angle, and may be the attack angle as well depending on the control strategy.

The orientation mechanism may act on the kite tethers starting from the ground, and in this case there are usually 2 or 4 tethers; or it can be up close to the kite, as shown in Fig.1, and in this case it receives the control signals from the ground station through a wireless connection.

It is worth mentioning here that, the number of the tethers is important, because their weight and drag force have a negative effect on the maximum average power that can be extracted from the system. On the other hand, having the wireless connection has its negative points also, as it is subjected to communication disturbances and failures.

In this paper, only optimizing the kite orbit will be presented, while the trajectory tracking aspect will be the center of another study.

\section{B. Power Transformation}

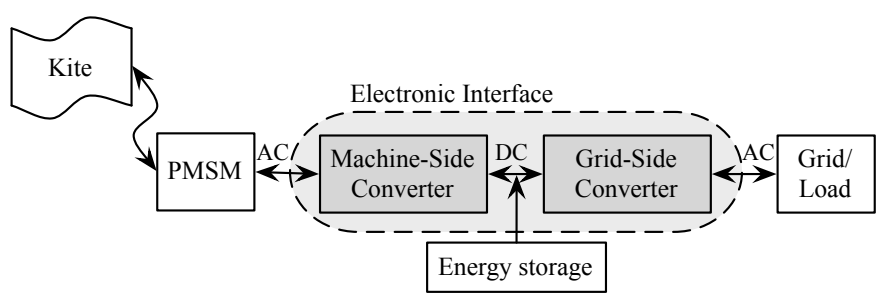

Fig. 2. Kite Generator System Block diagram.

In order to inject the extracted power into the electric grid or use it to supply a certain load, the block diagram of Fig.2 is proposed. The traction force of the kite is transformed into a torque applied on a permanent magnets synchronous machine (PMSM) situated on the ground. This leads to producing an alternative electrical energy with variable frequency. The machine is coupled with the grid, or with a certain load, through a power electronics interface that consists of two bidirectional AC/DC converters. An energy storage should be integrated in the case of a load or an isolated grid connection, 
in order to provide the necessary energy during the system's recovery phase.

While a lot of research is being done to optimize the kite orientation control [20] [21] [12], the grid connection part is yet to be treated. In this paper, the case of an infinite grid is handled.

\section{ModelLING}

Finding the model of each part of the KGS is a very important step to achieve better understanding of its behavior, thus better controlling. This section presents the modeling of the kite and the power transformation system. Found models will be implemented on Matlab/Simulink in order to test the later-explained control strategy (section IV). In the presented modeling, the following hypotheses are considered:

- A single-point model for the kite and the tether is adapted. Such a model is a rough one as it ignores the kite flexibility and deformations. It is, however, used usually to estimate the generated power.

- The tether is inelastic and straight. This hypothesis is correct when the tether's length is less than $1000 \mathrm{~m}$ and its inclination is less than 80 degrees [22].

- Wind is uniform with a non-varying direction, that is because the wind speed at high altitudes is regular.

- The geometry of the tether allows neglecting its lift force, and considering only the drag $C_{d t}$.

- The kite attack angel $\alpha$ is controlled to be null, hence both lift and drag coefficients $\left(C_{L}, C_{D}\right)$ are constants.

- A high effective aerodynamic efficiency $G_{e}$ of the kite and the tether. This factor is introduced in [23] by:

$$
G_{e}=\frac{C_{L}}{C_{D}+\frac{A_{c}}{4 A} C_{d t}}
$$

with $A$ is the kite surface and $A_{c}$ is the crosswind area of the tether.

- Kite's position and velocity as well as the traction force are known throughout the system's functioning using observers or sensors.

The previous assumptions cannot be applied if the interest is to study the control and the stability of the orientation system. Here, however, the interest is to study the grid connection part and to estimate the power generated by such a system.

\section{A. The Kite Dynamics}

The kite dynamic model originally developed in [24] and used in [25] is adapted here. As illustrated in Fig.3, forces acting on the system (kite+tether) include the gravity force $F_{\text {grav }}$, the apparent force $F_{a p p}$, the lift and drag aerodynamic forces $F^{a e r}$ and the tether traction force $F_{\text {trac }}$, the dynamics can be expressed in the spherical coordinates as follows:

$$
\left[\begin{array}{c}
m r \ddot{\theta} \\
m r \sin \theta \ddot{\phi} \\
\left(m+\frac{I}{R^{2}}\right) \ddot{r}
\end{array}\right]=F^{g r a v}+F^{a p p}+F^{a e r}+F_{t r a c}
$$

$I$ is the total inertia of the SMPM and drum; and $R$ is the drum

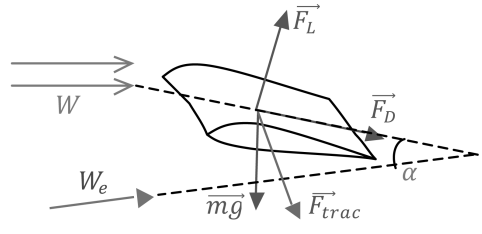

Fig. 3. Kite's main forces.

diameter. The gravity and the apparent forces are expressed in eq. 3 and eq. 4 .

$$
\begin{gathered}
F^{g r a v}=m g\left[\begin{array}{c}
\sin \theta \\
0 \\
-\cos \theta
\end{array}\right] \\
F^{a p p}=m\left[\begin{array}{c}
r \dot{\phi}^{2} \sin \theta \cos \theta-2 \dot{r} \dot{\theta} \\
-2 \dot{\phi}(\dot{r} \sin \theta+r \dot{\theta} \cos \theta) \\
r\left(\dot{\theta}^{2}+\dot{\phi}^{2} \sin ^{2} \theta\right)
\end{array}\right]
\end{gathered}
$$

where $m$ is the kite mass The aerodynamic force $F_{a e r}$ is related directly to the effective wind and $W_{e}$, that is the difference between the wind speed and the Kite's velocity. Assuming the wind speed is $V_{v}$ is in the direction of x-axis, $W_{e}$ is given by eq.5.

$$
W_{e}=\left[\begin{array}{c}
W_{e \theta} \\
W_{e \phi} \\
W_{e r}
\end{array}\right]=\left[\begin{array}{c}
V_{v} \cos \theta \cos \phi-\dot{\theta} r \\
-V_{v} \sin \phi-\dot{\phi} r \sin \theta \\
V_{v} \sin \theta \cos \phi-\dot{r}
\end{array}\right]
$$

$F_{\text {aer }}$ has two components: a $\operatorname{drag} F_{D}$ and a lift force $F_{L}$. Considering the notations:

$$
\begin{gathered}
L=\sqrt{W_{e \theta}^{2}+W_{e \phi}^{2}} \\
\eta=\arcsin \frac{W_{e r} \tan \psi}{L}
\end{gathered}
$$

The drag and lift are written in eq.7 and eq.6,

$$
\begin{gathered}
F_{D}^{a e r}=\frac{1}{2} \rho_{a} A\left(C_{D}+\frac{A_{c} C_{d t}}{4 A}\right)\left|W_{e}\right| \vec{W}_{e} \\
F_{L}^{a e r}=\frac{1}{2} \rho_{a} A C_{L}\left|W_{e}\right| \sin \psi\left[\begin{array}{c}
W_{e \phi} \\
-W_{e \theta} \\
0
\end{array}\right] \\
+\frac{1}{2} \rho_{a} A C_{L}\left|W_{e}\right| \cos \psi\left[\begin{array}{c}
\frac{W_{e r}}{L}\left[W_{e \phi} \sin \eta-W_{e \theta} \cos \eta\right] \\
\frac{-W_{e r}}{L}\left[W_{e \theta} \sin \eta+W_{e \phi} \cos \eta\right] \\
L \cos \eta
\end{array}\right]
\end{gathered}
$$

with $\rho_{a}$ is the air density. By combining and developing eq.2, the resulted system dynamics can be written as follows:

$$
\begin{aligned}
& \ddot{\theta}=f_{1}(\theta, \phi, r, \dot{\theta}, \dot{\phi}, \dot{r}, \psi) \\
& \ddot{\phi}=f_{2}(\theta, \phi, r, \dot{\theta}, \dot{\phi}, \dot{r}, \psi) \\
& \ddot{r}=f_{3}\left(\theta, \phi, r, \dot{\theta}, \dot{\phi}, \dot{r}, \psi, f_{\text {trac }}\right)
\end{aligned}
$$




\section{B. The Kite Refined Mathematical Model Average Power}

The system average mechanical energy over one period $T$ is the product of the traction force and tether length variation rate: the radial velocity $V_{L}$.

$$
\bar{P}_{M}=\frac{1}{T} \int_{0}^{T} F_{t r a c}(t) V_{L}(t) d t
$$

According to [19], by changing the integral time variable $t \in[0, T]$ to the dimensionless parameter $\tau \in[0,2 \pi]$, and making use of the substitution $V_{L}(t)=V_{v} v(\tau)$, eq.(9) can be developed to:

$$
\bar{P}_{M}(v)=\frac{1}{2} \rho_{a} A C_{L} G_{e}^{2} V_{v}^{3} J_{\chi}(v)
$$

with $J_{\chi}$ represents the normalized ${ }^{2}$ average power, and is expressed in eq. 11 .

$$
J_{\chi}(v)=\frac{\int_{0}^{2 \pi} \frac{\left[(c-v)^{2}-\chi \cos \theta\right] v}{w_{\| \mid}-v} h(\tau) d \tau}{\int_{0}^{2 \pi} \frac{h(\tau)}{w_{\|}-v} d \tau}
$$

with $w_{\|}=\sin \theta \cos \phi$ is the normalized wind velocity radial component, and:

$$
\begin{aligned}
h(\tau) & =\sqrt{d \theta^{2}+d \phi^{2} \sin ^{2}(\theta)} \\
\chi & =\frac{2\left(m+m_{t}\right) g}{\rho_{a} A C_{L} G_{e}^{2} V_{v}^{2}}
\end{aligned}
$$

\section{Power Transformation System}

To insert the kite's generated mechanical power into the electrical grid, a power transformation system is needed to transform this power into electrical power with grid's standard voltage and frequency. Such a system consists mainly of a permanent-magnets synchronous machine (PMSM), and a power electronics interface. The power transformation system is presented and modeled in the coming paragraphs.

1) Torque Transmission between the Kite and the PMSM: The translation movement of the tether is transformed to a rotation by means of a drum coupled to the PMSM through a gearbox. Thus, the traction force $F_{\text {trac }}$ is translated to a resistive torque $C_{R}$ applied on the machine. Torque transmission is expressed by the fundamental mechanical equation of eq.13 and Fig.4.

$$
C_{G}-C_{R}-D \Omega_{S}=J \frac{d \Omega_{S}}{d t}
$$

where:

- $\Omega_{S}=\frac{V_{L}}{K}$ is the rotation velocity, with $K$ combines the gear box factor and the drum diameter $R$.

- $J$ is the total inertia of the kite, the drum; and the machine's rotor.

- $C_{G}$ is the generator torque.

- $D$ is the damping factor estimation.

Eq.13 shows that in order to control the rotation velocity, a generator torque control should be applied, and vice-versa.

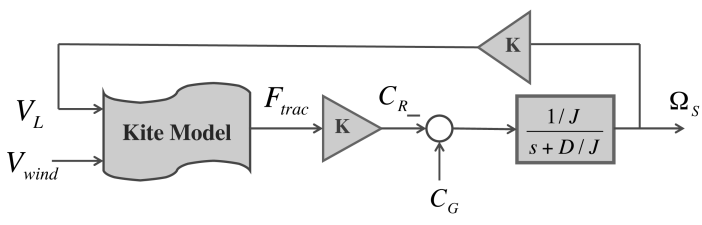

Fig. 4. Modeling of the mechanic connection between the kite and the electrical machine.

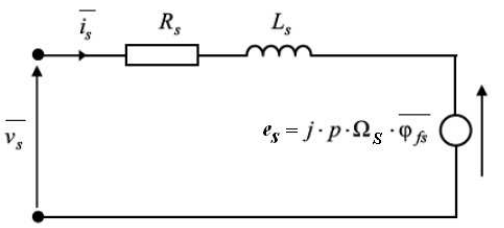

Fig. 5. PMSM's Behn-Eschenburg equivalent electrical model.

2) The PMSM's Vector Model: Each machine's phase can be presented by the Behn-Eschenburg equivalent electric model of Fig.5, which consists of a resistance $R_{s}$, inductance $L_{s}$ and an electromagnetic force $e_{s *}: *=a, b, c$. The model supposes the existence of a regular air gap, linear characteristics of the magnetic circuit (no saturation), and a balanced sinusoidal three-phase current behavior.

To visualize the three phases at the same time, variables' vector presentation is used, and is expressed in Park coordinates $(p, q)$ by

$$
\begin{aligned}
v_{S d} & =R_{S} i_{S d}+L_{s} \frac{d i_{S d}}{d t}-\omega L_{S} i_{S q} \\
v_{S q} & =R_{S} i_{S q}+L_{s} \frac{d i_{S q}}{d t}+\omega L_{S} i_{S d}+\omega \phi_{f S d} \\
\phi_{S d} & =L_{S} i_{S d}+\phi_{f S d} \\
\phi_{S q} & =L_{S} i_{S q} \\
C_{G} & =p \phi_{f S d} i_{S q}
\end{aligned}
$$

where

- $\overline{v_{s}}=v_{S d}+j \cdot v_{S q}$ is stator voltages' vector.

- $\overline{i_{s}}=i_{S d}+j . i_{S q}$ is stator currents' vector.

- $\bar{\phi}_{f s}=\phi_{f S d}+j . \phi_{f S q}$ is the induced flow vector.

- $p$ is the number of poles' pairs.

- $\omega=p \Omega_{S}$ is the electric pulsation.

Moreover, the electromagnetic torque is expressed by:

$$
C_{G}=p \cdot \operatorname{Imag}\left(\overline{i_{s}} \cdot \phi_{f s}^{*}\right)
$$

3) Power Electronics Interface: The interface ensures frequency and voltage isolation between the PMSM and the electric grid or the connected loads, and at the same time it offers the possibility of power flow from/to the PMSM. This interface is made up of two converters $\mathrm{AC} / \mathrm{DC} \& \mathrm{DC} / \mathrm{AC}$ that converts the variable frequency/voltage electric power generated by the PMSM, into a standard frequency/voltage electric power that can be injected into the grid after an filtering stage. The nature of the filter depends on the connection type. In Fig7, a filter $L$ is used to connect the system to an infinite electric grid.

The structure chosen for this interface is two three-phase transistor-based voltage converters (Figs.6 and 7) [26], controlled using vector pulse width modulation (PWM). Both

${ }^{2}$ Normalizing factor is : $\rho_{a} A C_{L} G_{e}^{2} V^{3}$ 


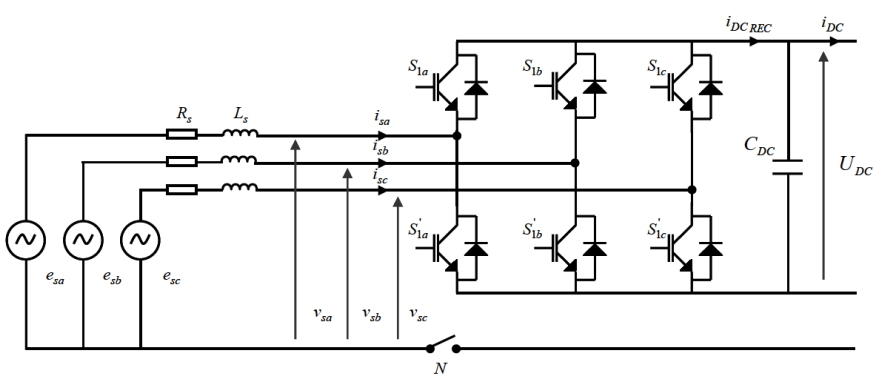

Fig. 6. Electric representation of the PMSM-side converter. PMSM is presented by Behn-Eschenburg model. $C_{d c}$ is DC-bus filtering capacitor.

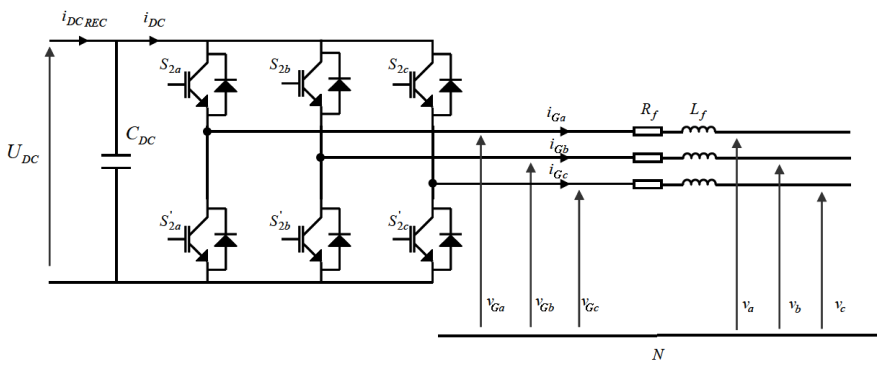

Fig. 7. Electric representation of the Grid-side converter. $R_{f}$ and $L_{f}$ represent loss and filtering components.

converters function as a rectifier and an inverter depending on the system's phase (Generation or recovery phase), insuring a bi-directional transfer of energy.

Supposing that the converter's transistors and voltage sources are perfect, and the passive elements are linear and constant, Park representation of the average converter model is written as follows:

$$
\begin{array}{ll}
L_{s} \frac{d i_{s d}}{d t} & =\beta_{s d} \frac{U_{D C}}{2}+\omega L_{q} i_{s q}-R_{s} i_{s d} \\
L_{s} \frac{d i_{s q}}{d t} & =\beta_{s q} \frac{U_{D C}}{2}-\omega L_{d} i_{s d}-R_{s} i_{s q}-e_{s q} \\
C_{D C} \frac{d U_{D C}}{d t} & =I_{D C}-\left(\beta_{s d} \frac{i_{s d}}{2}+\beta_{s q} \frac{i_{s q}}{2}\right)
\end{array}
$$

where $U_{D C}$ and $I_{D C}$ are the DC bus voltage and current respectively.

The same modeling approach is applied in the case of the grid-side converter (Fig.7), which results in:

$$
\begin{aligned}
& L_{f} \frac{d i_{G d}}{d t}=-\beta_{G d} \frac{U_{D C}}{2}+\omega_{G} L_{f} i_{G q}-R_{f} i_{G d}+\sqrt{3} V_{G} \\
& L_{f} \frac{d i_{G q}}{d t}=-\beta_{G q} \frac{U_{D C}}{2}+\omega_{G} L_{f} i_{G d}-R_{f} i_{G q} \\
& C_{D C} \frac{d U_{D C}}{d t}=I_{D C_{R E C}}-\left(\beta_{G d} \frac{i_{G d}}{2}+\beta_{G q} \frac{i_{G q}}{2}\right)
\end{aligned}
$$

where:

- $\omega_{G}$ is the electric grid pulsation of $v_{\text {res }}$.

- $V_{G}$ is the grid RMS voltage.

- $i_{G}^{-}=i_{G d}+i_{G q}$ is the grid currents' vector.

- $I_{D C_{R E C}}$ is the machine converter output current.

As noticed, an average model is adapted in order to have a continuous time model without switching, which allows the usage of relatively large sampling time in simulations.

\section{THE CONTROL STRATEGY}

The KGS control strategy proposed in this paper is divided into two objectives: the first aims at generating the optimal tether's radial velocity and the period corresponding to a given eight-figured orbit. The second aims at implementing a control method that allows tracking the generated orbit while respecting the system's constraints. This is done via control of the kite roll angle and the tether's radial velocity.

\section{A. Reference Orbit Generation}

Based on [19], the optimization procedure starts from an initial kite orbit characterized by the tether's initial length $r_{0}$, and the parameters defining $\theta$ 's and $\phi$ 's variations space: $\Delta \theta, \Delta \phi, \theta_{0}, \phi_{0}$ and $\operatorname{Rot}$ (see Fig.8). From these parameters, it finds the normalized radial velocity profile $\hat{v}(\tau)$ which maximizes the power expressed in eq.10, and respects the kite's closed orbit condition $\int_{0}^{T} V_{L}(t) d t=0$ which can be equally written as in eq. 18 .

$$
\int_{0}^{2 \pi} \frac{v h(\tau)}{w_{\|}-v} d \tau=0
$$

Once found, $\hat{v}(\tau)$ is used to derive the traction force [19] by:

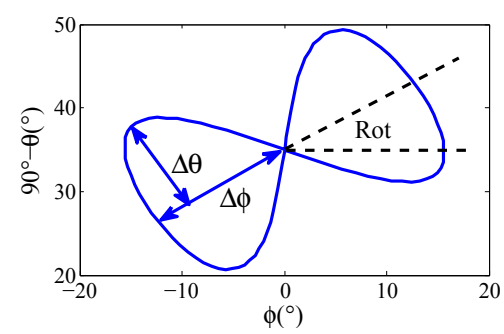

Fig. 8. Initial orbit parameters.

$$
f_{\text {trac }}=\frac{1}{2} \rho_{a} A C_{L} G_{e}^{2} V_{v}^{2}\left(w_{\|}-\hat{v}\right)^{2}-\left(m+m_{t}\right) g \cos \theta
$$

Since all done calculations and variables are functions of the dimensionless parameter $\tau$ and have a period of $2 \pi$. The relation between the time variable $t \in[0, T]$ and $\tau$ need to be defined. It is expressed by eq.20 [19].

$$
t=\int_{0}^{\tau} \frac{r . h}{\omega_{\perp}+\sqrt{\omega_{\perp}^{2}+G_{e}^{2}\left(w_{\|}-v\right)^{2}-\left|w_{\perp}\right|^{2}}} d \sigma
$$

\section{B. Orbit Tracking}

The resulted kite orbit is a three-dimensional orbit described in the spherical coordinates by $r(t), \theta(t), \phi(t)$. Tracking this orbit is divided into orienting the kite hence controlling its roll angle to follow the reference $(x, \dot{x}): x=(\theta, \phi)$, and controlling the radial velocity by control of the PMSM rotation velocity $\left(V_{L}=\Omega_{S} / K\right)$.

Many methods are proposed to achieve $x$ tracking [12], since this topic is not the focus of this paper, only the result of applying an optimal control will be shown later in section $\mathrm{V}$. At every time step, $\ddot{x}$ that minimizes the cost function of eq.21 is calculated and controlled by the roll angle $\psi$.

$$
f=\left\|\left(\ddot{x}_{r e f}-\ddot{x}\right)+\lambda_{1}\left(x_{r e f}-x\right)+\lambda_{2}\left(\dot{x}_{r e f}-\dot{x}\right)\right\|^{2}
$$

where $\lambda_{1}, \lambda_{2}$ determine how quickly the state converges to the reference orbit. 
Fig.9 shows the general control scheme of the power transformation system. As mentioned earlier, the KGS is connected to an infinite electric grid, so the control strategy aims at extracting the maximum possible energy and inject it in the grid, while the grid will be responsible of supplying the necessary energy during the recovery phase.

The PMSM's rotational velocity control and the generator torque control are guaranteed by the PMSM-side converter. The kite applies a resistive torque $C_{R}$ that gives, when inserted in the mechanical equation, the rotation velocity $\Omega_{S}$. The velocity is corrected using a PI controller that yields a reference generator torque $C_{G r e f}$.

The purpose of the grid-side converter is to convert the direct power to a fixed-frequency alternative power, or vice versa, hence, it is driven to control the DC-bus voltage.

The control scheme can be divided into three levels:

1) Low Level Control: Considering a Surface PMSM and taking into account that the machine and its converter are working within their nominal limits; controlling the generator torque $C_{G}$ is equivalent to controlling the current $i_{s q}$ with asserting $i_{s d}=0$. This allows having a maximum torque per ampere (MTPA). The current controller generates the pulse width modulation PWM commutation rates that drive the converters' transistors. For the machine-side converter, this is done by controlling the converter currents, while for the gridside converter; it is done by controlling the current if connected to an infinite grid.

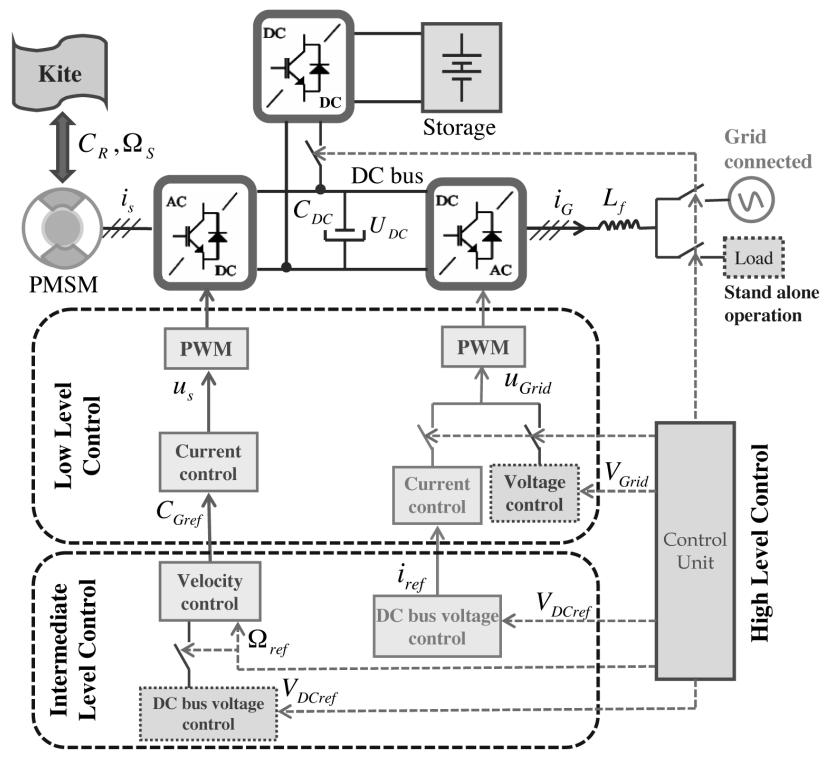

Fig. 9. General control scheme of the kite-based system. Two control tracks applied depending whether the system is grid connected or in a stand-alone operation.

2) Intermediate Level Control: In the case of an infinite grid connection, this level generates the references needed for the currents in the lower level. The machine-side converter reference currents are generated by the rotation velocity controller; meanwhile, those of the grid-side converter are generated by the DC-bus voltage controller.

3) High Level Control: In addition to generating the reference signals of the needed lower control levels, the high level control supervises the functioning of the system by controlling the switches that determine the power flow through it.

In the case of absence of wind speed measurement, the optimal radial velocity can be calculated according to standard wind-altitude curves, while a maximum power point tracking (MPPT) algorithm acts on the rotation velocity amplitude to find the optimal profile. The proposed algorithm is a simple "Perturbation \& Observation" algorithm that calculates the average power during a period, then compares it with the power obtained during the previous period. The algorithm then applies the optimal radial velocity after multiplying it with a suitable gain. The algorithm is effective to deal with slow changes in wind speed compared to the orbit's period, which is usually valid for high altitude winds. When it comes to a stand alone operation case, the control levels varies slightly, because the goal becomes generating the needed power and not the maximum. As a result, the machine-side converter is driven to control the DC-bus voltage and the grid-side converter controls the output voltage.

\section{Simulation and Results}

As previously mentioned, the goal of this paper is to introduce, model and study the integration of the KGS on the electric grid. In this context, a simplified closed-orbit KGS with application of MPPT algorithm and integration on an infinite electric grid is taken into consideration.

Choosing the primary orbit to be optimized is very important in determining the maximum possible extracted average power, and the ratio between the maximum power and the average, or what we chose to call "Performance". In [13], it was demonstrated that a bigger trajectory correspond to greater average power, further more, a bigger rotation of the orbit leads to more average power. Taking into account these two facts while respecting the limits on the velocity and the resistive torque imposed by the HIL simulator [27] that will be used to test practically the functioning of the system, the employed KGS's parameters are shown in Table.I.

TABLE I

Kite Generator System Parameters

\begin{tabular}{|l||l||l|}
\hline$K$ & 414 & Gearbox factor * rotor diameter $R(\mathrm{~m})$ \\
\hline$V$ & 4 & Wind speed $(\mathrm{m} / \mathrm{sec})$ \\
\hline$\Omega_{\max }$ & 210 & Maximum rotation velocity (rd/sec) \\
\hline$\Gamma_{\max }$ & 30 & Motor maximum torque $(\mathrm{N} . \mathrm{m})$ \\
\hline$p$ & 4 & Pole's pairs number \\
\hline$A, m$ & 5,3 & Kite's area $\left(\mathrm{m}^{2}\right)$ and mass $(\mathrm{Kg})$ \\
\hline$\rho_{a}$ & 1.2 & Air density $\left(\mathrm{kg} / \mathrm{m}^{3}\right)$ \\
\hline$C_{L}, C_{D}$ & $1.2,0.08$ & Lift and drag coefficient of the KGS \\
\hline$r_{0}$ & 600 & Initial tether length $(\mathrm{m})$ \\
\hline
\end{tabular}

The testing orbit is defined by the parametric equations eq.22 with a rotation $90^{\circ}$.

$$
\theta(\tau)=55^{\circ}+10^{\circ} \sin (2 \tau), \phi(\tau)=15^{\circ} \sin (\tau)
$$

with $\tau \in[0,2 \pi]$. As noticed the orbit initial inclination is 55 which does not agree with the condition that let the assumption 
"The tether is straight and inelastic" true. But, with a a tether's crosswind area much smaler than the kite surface, according to 6, the tether's drag force can be neglected infront of the kite traction force, so the previous assumption applies here. Applying the optimization algorithm results in the optimal radial velocity shown in Fig.10 with a period $T=20.6 \mathrm{sec}$.

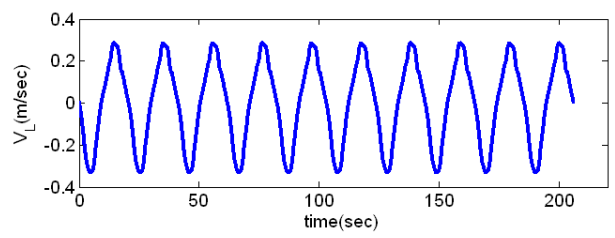

Fig. 10. Optimal normalized radial velocity.

An optimal control that minimizes the cost function of eq.21 is applied to find the roll angle needed for the kite to track the optimal orbit. The resulted trajectory is shown on Fig.11. The tether's optimized radial velocity $V_{L}$ as well as traction force $F^{c, t r c}$ obtained from the kite model are transformed into a rotation velocity $\Omega_{S}$ and a resistive torque $C_{R}$ of the rotor (see Fig.4). The transformation is done through a drum coupled to the PMSM through a gearbox. The simplest representation of this transformation is a multiplication by a constant as in the following equations:

$$
\Omega_{S}=V_{L} K, C_{R}=\frac{F^{c, t r c}}{K}
$$

In order to adapt to the HIL Simulator, the product factor is found to be $K=414$.

The optimization is done off-line, and the obtained $\Omega_{S}$ and $C_{R}$ are then applied on the power transformation system Simulink model. The MPPT algorithm will, as explained in section IV-B3, modify the amplitude of the optimal radial velocity to follow slow changes of wind speed. To test the functioning of the MPPT algorithm, the wind speed is changed from $4 \mathrm{~m} / \mathrm{sec}$ to $5 \mathrm{~m} / \mathrm{sec}$. Fig. 12 shows the modification of the velocity amplitude because of the MPPT algorithm, and the resulted resistive torque; and finally the development of the average power per period. The maximum power point (MPP) is seemed to be tracked in 3 times the orbit period which is about $60 \mathrm{sec}$. The simulation shows that the estimated average produced power of the system, described in Table.I, at a wind speed $5 \mathrm{~m} / \mathrm{sec}$ is $400 \mathrm{~W}$.

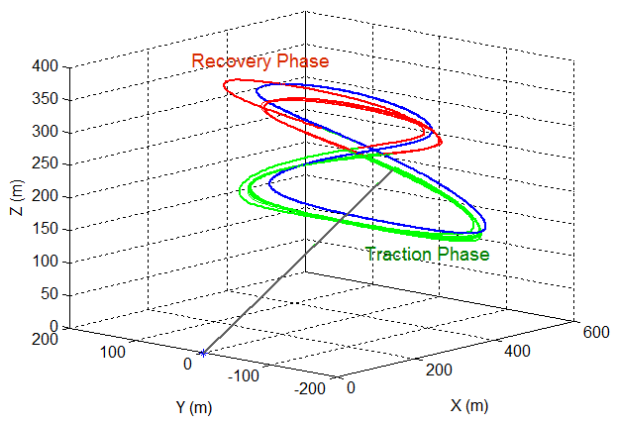

Fig. 11. Orbit Tracking using optimal predictive control. In green: Traction phase, in red: Recovery phase.
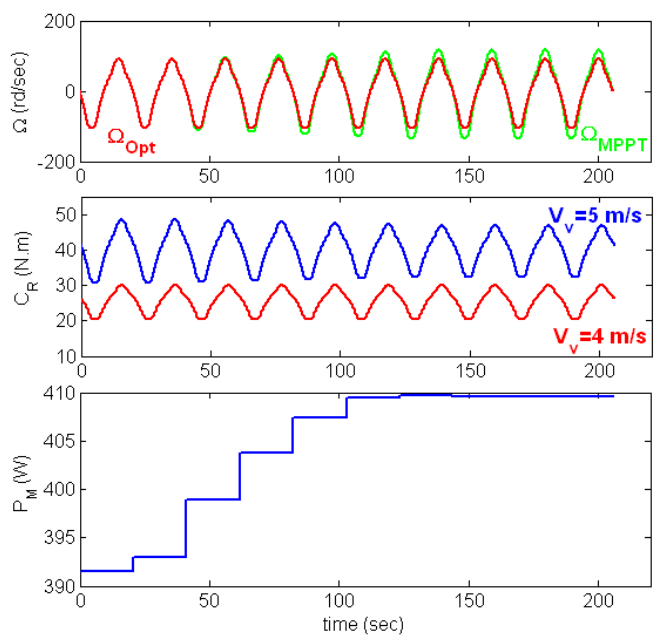

Fig. 12. Application of MPPT algorithm on the rotation velocity when wind speed changes from 4 to $5 \mathrm{~m} / \mathrm{s}$ at instant $40 \mathrm{sec}$. Upper plot: In dashed red, the optimization resulted rotation velocity, in continuous blue, the MPPT rotation velocity. Center plot: The resistive torque $\left(C_{R}\right)$, in dashed red, at wind speed $4 \mathrm{~m} / \mathrm{sec}$, in continuous blue, at $5 \mathrm{~m} / \mathrm{sec}$. Lower plot: The average mechanic power.

The next step is to transform the mechanical power produced by the PMSM into an electrical power that can be injected into the grid. This can be insured by tuning different control levels paremeters presented in the general control scheme (Fig.9). Classical PID regulators are used to control the velocity and the currents of the machine-side converter, while for the gridside converter's currents a resonant PID is implemented.

Figs.13 shows the machine phase current $I_{a S}$ and the DC bus $U_{D C}$ voltage during one period of the rotation velocity $\Omega_{S}$. It can be noticed that $U_{D C}$ is well controlled with an error less than $0.9 \%$. Fig. 14 shows a grid phase current $I_{a-G}$ and the grid phases voltages $V_{a, b, c-G}$. The grid-side converter was successfully controlled to provide the grid with a standard three-phase voltage, and the current has only the $50 \mathrm{~Hz}$ harmonic.

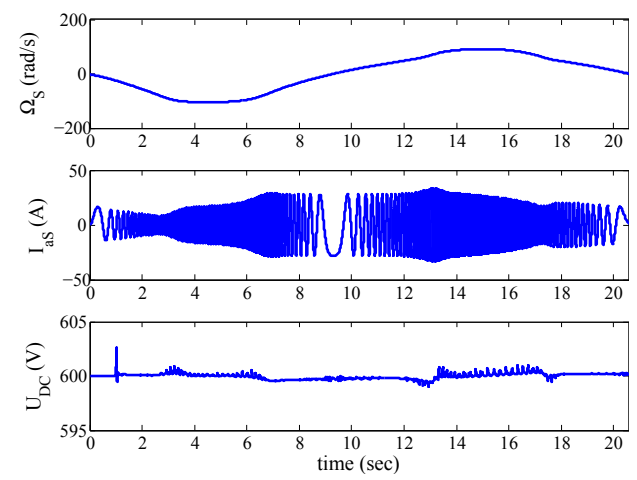

Fig. 13. Starting from the upper plot: The PMSM rotation velocity $\left(\Omega_{S}\right)$, PMSM phase current $\left(I_{a S}\right)$, DC bus voltage $\left(U_{D C}\right)$.

The previous simulation results are a first and initial step towards the HIL (Hardware in the loop) validation. We remind here that until now the control strategy is divided into two "independent" problems, the kite orientation, that is control of $\theta, \phi$ through the roll angle $\psi$, and the radial velocity control $\dot{r}$ 
through driving of the PMSM. Hence the MPPT algorithm acts only on the $\dot{r}$ regardless of the kite orbit. A further work will merge both control problems, and will use a more developed MPPT algorithm that considers changing the kite orbit itself to maximize the extracted average power.
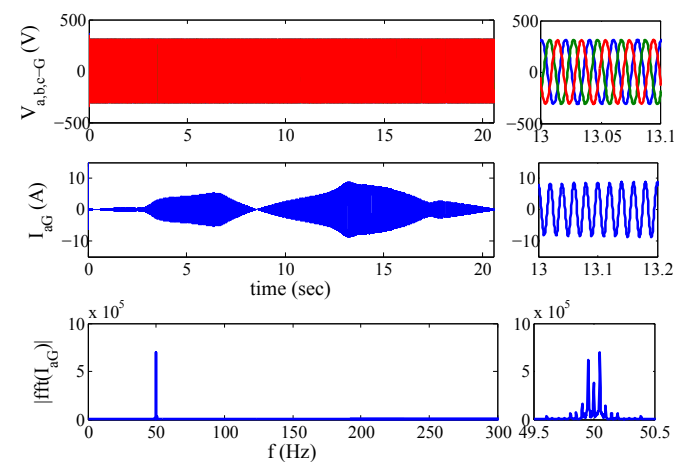

Fig. 14. Starting from upper figure: Grid voltages, grid current $\left(I_{a G}\right)$, its frequency analysis.

\section{Discussion:}

The closed-orbit KGS is not suitable to compare the potential of using kites to produce electrical power to that of classical wind turbines, as its energy efficiency is small compared to the pumping KGS or a closed-orbit configuration with a variable aerodynamic efficiency $G_{e}$.

TABLE II

ENERCON E33 MAIN CHARACTERISTICS

\begin{tabular}{|l||l|}
\hline Rated Power & $300 \mathrm{~kW}$ \\
\hline Hub height & $50 \mathrm{~m}$ \\
\hline Rotor diameter & $33.4 \mathrm{~m}$ \\
\hline Rated wind speed & $11.7 \mathrm{~m} / \mathrm{s}$ \\
\hline
\end{tabular}

Nevertheless, a small Enercon wind turbine (E33) rated power of $330 \mathrm{~kW}$ can be obtained using the closed-orbit KGS described by eq.22 and in Table.I but with a kite surface $A=300 \mathrm{~m}^{2}=30 \mathrm{~m} \times 10 \mathrm{~m}$. The flying part of such a system, including: the kite and the orientation mechanism will have a mass of less than $1 t$ compared to about $18.7 t$ for the E33 turbine's on-tower mass, eg: excluding the tower and the turbine foundation. This fact makes the KGS easier to be transfered and maintained. On the other hand, both wind system occupy theoretically the same ground area. But when it comes to aerial area, the KGS's power per unit area for this example seems to be about 60 times less than that of the E33, the same system can be used to produce more power by simply changing the kite's altitude. As well, working at high altitude ensures a constant high wind speed hence constant power generation.

As mentioned before, the KGS will offer a very high adaptivity, as its rated power can be modified by changing the kite orbit eg. size, rotation and/or inclination, or changing the altitude at which the kite is flying for example. Fig. 15 shows how the KGS generated average power changes as a function of the kite surface $A$, the orbit rotation angle; and the orbit inclination $\theta_{0}$.
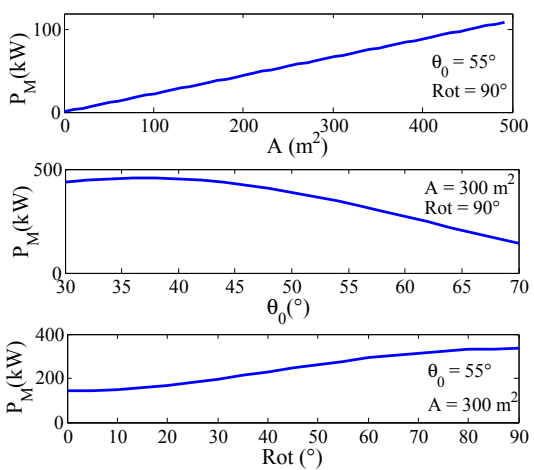

Fig. 15. Starting from upper plot: The average mechanic power as a function of the kite surface $A$, the inclination angle $\theta_{0}$; and the orbit rotation Rot.

\section{CONClusion AND PRespectives}

In the search for alternatives to fossil fuel energy, high altitude wind energy (HAWE), and more specifically Kites or airborne wind energy (AWE), are receiving an increasing interest at present.

In this paper, a grid-connected closed-orbit kite generator system with application of MPPT algorithm was considered. For an eight-form orbit, the optimal radial velocity of the tether was calculated for a specific wind speed. Using the kite model, the kite's traction force was calculated, and the corresponding resistive torque was applied on a Matlab/Simulink model of a power transformation system that consists of a Permanent Magnet Synchronous Machine and a power electronics interface. A maximum power point tracking (MPPT) algorithm was applied on the PMSMs rotation velocity in order to insure maximum power production in the case of slow wind speed variations.

By controlling the PMSM rotation velocity to follow the reference velocity profile generated by the MPPT algorithm, and controlling different electrical variables loops, a maximum power corresponding to the given orbit was generated and successfully integrated into the grid.

The KGS will offer a very high adaptivity, as its rated power can be modified by changing the kite orbit or altitude. Moreover, the system will be much easier and cheaper to be maintained. It is, however, more complex to be modeled and controlled in real time, a matter that will not be a problem thanks to the rapid development in computer and information technology, allowing to have fast and reliable real-time data processing.

As for experimental validation, the simulation results obtained in this paper will be applied to a HIL (Hardware in the loop) physical simulator that is dedicated to real-time validation of control laws with insertion of physical elements that contribute to better replication of the real phenomena. As well, a reduced kite's model is under construction, and will be used to test the proposed control strategy.

\section{REFERENCES}

[1] A. W. E. A. (AWEA), "U.S. wind industry annual market report: year ending 2009," Washington, D.C., 2010.

[2] C. Archer and M. Jacobson, "Evaluation of global wind power," Journal of Geophysical Research, vol. vol.110, D12110, 2005. 
[3] G. Masters, Renewable and Efficient Electric Power Systems. John Wiley \& Sons, Inc., Hoboken, New Jersey., 2004.

[4] O. Ceyhan, "Towards 20mw wind turbine: High reynolds number effects on rotor design," Wind Energy, vol. 2011, p. 2010, 2012.

[5] F. Grasso, "Development of thick airfoils for wind turbines," 50th AIAA Aerospace Sciences Meeting including the New Horizons Forum and Aerospace Exposition, Nashville, Tennessee, 09 - 12 January 2012.

[6] http://www.magenn.com/, Std.

[7] J. Kolar, T. Friedli, F. Krismer, A. Looser, M. Schweizer, P. Steimer and J. Bevirt, "Conceptualization and multi-objective optimization of the electric system of an airborne wind turbine," in Industrial Electronics (ISIE), 2011 IEEE International Symposium on. IEEE, 2011, pp. 32-55.

[8] http://www.makanipower.com/.

[9] http://www.jobyenergy.com/.

[10] I. Argatov, P. Rautakorpi, and R. Silvennoinen, "Estimation of the mechanical energy output of the kite wind generator," Renewable Energy, vol. 34, pp. 1525-1532, 2009.

[11] M. Loyd, "Crosswind kite power," J. ENERGY, vol. 4(3), 1980.

[12] M. Ahmed, A. Hably, and S. Bacha, "High altitude wind power systems: A survey on flexible power kites," International Conference on Electrical machines, Marseille, France, September 2012.

[13] I. Argatov and R. Silvennoinen, "Structural optimization of the pumping kite wind generator," Structural and Multidisciplinary Optimization, vol. 40, no. 1, pp. 585-595, 2010.

[14] B. Lansdorp and P. Williams, "The laddermill - innovative wind energy from high altitudes in holland and australia," in Windpower 06, Adelaide, Australia, 2006

[15] A. Podgaets and W. Ockels, "Flight control of the high altitude wind power system," in Proceedings of the 7th Conference on Sustainable Applications for Tropical Island States, 2007.

[16] B. Houska and M. Diehl, "Robustness and stability optimization of power generating kite systems in a periodic pumping mode," in IEEE Multi - Conference on Systems and Control, 2010, pp. 2172-2177.

[17] M. Canale, L. Fagiano, and M. Milanese, "High altitude wind energy generation using controlled power kites," IEEE Transactions On Control Systems Technology, vol. 18(2), pp. 279 - 293, 2010.

[18] R. Lozano Jr, M. Alamir, J. Dumon, and A. Hably, "Control of a wind power system based on a tethered wing," IFAC second EGNCA, Bangalore, India, February 2012.

[19] I. Argatov and R. Silvennoinen, "Energy conversion efficiency of the pumping kite wind generator," Renewable Energy, vol. 35(5), pp. 1052 1060, 2010.

[20] C. Novara, L. Fagiano, and M. Milanese, "Direct data-driven inverse control of a power kite for high altitude wind energy conversion," in IEEE International Conference on Control Applications (CCA), 2011, pp. 240-245.

[21] J. H. Baayen and W. Ockels, "Tracking control with adaption of kites," IET control theory \& applications, vol. 6, no. 2, pp. 182-191, 2011.

[22] D. Olinger and J. Goela, "Performance characteristics of a one-kilowatt scale kite power system," Proceedings of Energy Sustainability, 2008.

[23] B. Houska and M. Diehl, "Optimal control of towing kites," in 45th IEEE Conference on Decision and Control, pages 2693-2697, San Diego, CA, USA 2006.

[24] M. Diehl, "Real time optimization for large scale nonlinear processes," Ph.D. dissertation, University of Heidelburg, 2001.

[25] M. Canale, L. Fagiano, M. Ippolito, and M. Milanese, "Control of tethered airfoils for a new class of wind energy generator," in Proceedings of the 45th IEEE Conference on Decision and Control, 2006.

[26] I. Munteanu, A. Bratcu, S. Bacha, D. Roye, and J. Guiraud, "Hardwarein-the-loop-based simulator for a class of variable-speed wind energy conversion systems: Design and performance assessment," IEEE Transactions On Energy Conversion, vol. 25, pp. 564-576, JUNE 2010.

[27] I. Munteanu, A. Bratcu, M. Andreica, S. Bacha, D. Roye, and J. Guiraud, "A new method of real-time physical simulation of prime movers used in energy conversion chains," Simulation Modelling Practice and Theory, vol. 18 , p. $13421354,2010$.

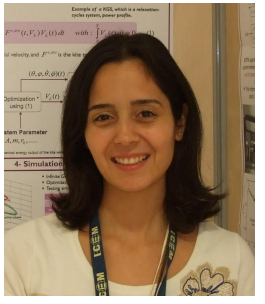

Mariam Ahmed (G2Elab), She received her Electronic Systems Engineering diploma at the Higher Institute of Applied Sciences and Technology (HIAST) in Damascus, Syria, Jan. 2007. She worked for a year as an assistant lecturer and project supervisor at the Electro-mechanical Systems Department in HIAST. In July 2010, she received the Master Research degree in Electrical Engineering in Grenoble Institute of Technology, France. Currently, she is pursuing her $\mathrm{PhD}$ degree in Electrical Engineering. Her research interest includes renewable energy generation systems, nonlinear control.

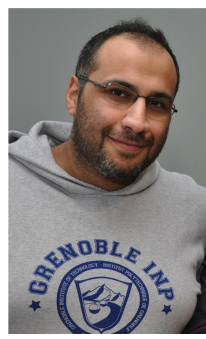

Ahmad Hably (GIPSA-lab), associate professor at Grenoble-INP. He received his B.S. degree in electrical engineering from the Lebanese University. At 2007, He received his $\mathrm{PhD}$ degree in Nonlinear control from the Grenoble Institute of Technology. After one year as researcher at LIRMM, he has joined the automatic control department of GIPSAlab at 2008. His research interests include nonlinear control systems, robotics, and smart grid. $\mathrm{He}$ is author of more than 5 journal papers, 14 international papers. Actually he is co-supervisor of $2 \mathrm{PhD}$ on control of high altitude power kites and their integration to the grid.

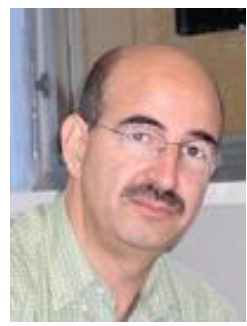

Seddik Bacha (M'08) received the Engineer and Magister degrees from cole Nationale Polytechnique de Algiers, Algeria, in 1982 and 1990,respectively, and the Ph.D. degree from Institut NationalPolytechniquedeGrenoble,France,in1993. He joined the Laboratoire dElectrotechnique de Grenoble (LEG) in 1990 and in 1998 he was habili- tated to conduct research. He is research officer with Grenoble Electrical Engineering Laboratory (G2ELab) and a Professor with the Joseph Fourier University of Grenoble. His research interests include power el ectronics system modeling and control, power quality, and renewable energy and non-conventional loads. 